\title{
Investigation of Atmospheric Aerosol Size Distributions from Ground- Based Solar Spectrometer Measurements Synthesized with Satellite Data
}

\author{
Dane T. Kubr* \& Adam T. Whitten \\ Physics Department, College of Saint Benedict/Saint John's University, Collegeville, $M N$ \\ bttps://doi.org/10.33697/ajur.2019.013 \\ Student:dkubr001@csbsju.edu* \\ Mentor:awbitten@csbsju.edu
}

\begin{abstract}
Data collected by a ground-based solar spectrometer at Collegeville, MN, was used to generate Aerosol Optical Depths (AODs) throughout the 2017 calendar year. The AOD data was then visualized at 13 selected wavelengths throughout the year and analyzed in comparison to satellite imagery, upper air charts and backwards trajectories of air masses moving towards Central Minnesota in order to determine key dates of interest that correspond to times before (20170615), during (20170729), and at the conclusion of (20170914) forest fires that burned in British Columbia (BC) during the summer of 2017. The data from these specific days were analyzed further by inputting the maximum and minimum AODs for each day into a Parameter Based Particle Swarm Optimization (PBPSO) algorithm in order to generate bimodal lognormal particle size distributions. The bimodal distributions were chosen because they carry more information about the aerosol loads across the entire spectrum of particle radii. The resulting distributions show an increase in number density and decrease in median radius in the Aitken mode during the BC forest fires and a relatively constant (within uncertainty) number density of accumulation mode particles at daily maximum AODs. Comparing the resulting bimodal lognormal distribution for daily minimum AODs (where evaporation and other diurnal effects are at a minimum) shows an increased number density of Aitken mode particles by two orders of magnitude from pre- to postforest fires. This measured increase in the number density of smaller radii particles due to forest fires illustrates the PBPSO's capability of distinguishing variations in atmospheric aerosol particle number size distributions in the Aitken mode based on data collected by the Kipp-Zonen PGS-100 solar spectrometer.
\end{abstract}

\section{KEYWORDS}

Atmospheric Aerosol; Particle Swarm Optimization; Aerosol Optical Depth; Solar Spectrometer; Size Distributions; Forest Fire; Satellite Imagery; Upper Air Charts; Backward Trajectory

\section{INTRODUCTION}

Atmospheric aerosols are of interest to members of the scientific community and the general public alike because they affect environmental conditions and public health. ${ }^{1-3}$ The environmental effects of aerosols depend on the particles' radii, ranging from $.001-100 \mu \mathrm{m},{ }^{2}$ chemical composition, and optical properties. ${ }^{3}$ Atmospheric aerosols contribute to regional climate change by absorbing and scattering radiation and acting as cloud condensation nuclei (CCN)., 5 Natural aerosols tend to be larger particles and are formed of plant matter, ash, sea salt, dust, and other aqueous chemicals. Anthropogenic aerosols, on the other hand, tend to be sub-micrometer particles formed by combustion emissions and in some cases are known toxins. ${ }^{6}$ These smaller anthropogenic aerosols are capable of traveling farther down the respiratory tract posing a major threat to public health. ${ }^{6}$ All atmospheric aerosols impact air quality ${ }^{3}$, visibility ${ }^{4}$ and climate change. ${ }^{7}$

Ground-based solar spectrometers are commonly used to measure solar irradiance values that relate to aerosol optical depth (AOD). In order to calculate AODs from irradiances measured by the PGS-100 spectrometer, it is necessary to calculate the irradiance across the entire spectrum. The irradiance measured at Earth's surface can be related to the irradiance at the top of Earth's atmosphere by taking into account absorption, Rayleigh scattering, and Mie scattering. Equation 1, outlined in London et al. 1985, yields irradiance as a function of wavelength: ${ }^{8}$

$$
L_{\lambda}=\frac{L_{\lambda_{0}}}{D^{2}}\left(e^{-\alpha \mathrm{X} \mu-m \beta \frac{P}{P_{0}}-\delta m^{\prime}}\right)
$$

Equation 1.

where $L_{\lambda_{0}}$ is the irradiance at the top of Earth's atmosphere at a distance of $1 \mathrm{AU},{ }^{9} L_{\lambda}$ is the irradiance measured by the PGS-100 spectrometer, $D$ is the distance from the Earth to the Sun in astronomical units (AU), $\alpha$ is the absorption coefficient of the 
absorption species in $\mathrm{cm}^{-1}, \mathrm{X}$ is the total thickness of absorber in a vertical column at STP $(\mathrm{cm})$, and $\mu$ is the ratio of actual and vertical paths of the light through the absorbing layer, $m$ is the optical path length allowing for refraction (atm), $\beta$ is the atmospheric Rayleigh scattering coefficient (atm), $P$ is the pressure at the point of measurement ( $\mathrm{mb}$ ), $P_{0}$ is the mean sea level pressure $(\mathrm{mb}), \delta$ is aerosol optical depth (dimensionless) and $m^{\prime}$ is $\sec \theta$ where $\theta$ is the solar zenith angle. ${ }^{8}$

Because this investigation focuses on 13 wavelengths avoiding absorption regions, the first term in the exponential in Equation 1 becomes negligible, and inversion into Equation 2 enables the calculation of aerosol optical depths based on measured irradiances.

$$
\delta=\frac{\ln \left(\frac{L_{\lambda} D^{2}}{L_{\lambda_{0}}}\right)-m \beta \frac{P}{P_{0}}}{m^{\prime}}
$$

Equation 2.

Instead of using Komhyr's expression for Rayleigh optical depth $\left(m \beta \frac{P}{P_{0}}\right)$, which assumes an atmospheric $\mathrm{CO}_{2}$ concentration of $300 \mathrm{ppm}$, this research uses the recommendation of Bodhaine et al. 1999. ${ }^{10}$ Bodhaine's method takes $\mathrm{CO}_{2}$ concentration into account by including its contribution to the scattering cross section of air (including the molecular mass, the index of refraction, density and the depolarization term or King factor). This research uses $\mathrm{CO}_{2}$ concentration measured at the Mauna Loa Observatory in Hawaii, resulting in Equation 3:

$$
\delta=\frac{\ln \left(\frac{L_{\lambda_{0}}}{L_{\lambda} D^{2}}\right)}{m^{\prime}}-\sigma \frac{P A}{m_{a} g}
$$

where $L_{\lambda_{0}}, L_{\lambda}, D, P$ and $m^{\prime}$ all represent the same values as above, $\sigma$ is the scattering cross section per molecule that accounts for increased partial pressure of increasing atmospheric $\mathrm{CO}_{2}$ levels, $A$ is Avogadro's number, $m_{a}$ is the mean molecular mass of air $(\mathrm{kg})$ and $g$ is the acceleration of gravity at the measurement site. ${ }^{10}$

A Parameter Based Particle Swarm Optimization algorithm described by DuPaul et al. 2017 can be applied to these inferred AODs in order to retrieve particle size distributions. ${ }^{11}$ This yields valuable information about the atmospheric aerosols which are highly heterogeneous in time and space. The PBPSO provides a reasonable, but computationally expensive means to find particle number size distribution fit parameters based on input AOD data. Bimodal distributions are of the form:

$$
n_{B}(r)=\frac{d N(r)}{d \ln (r)}=\frac{N_{0}}{\sqrt{2 \pi}} \frac{1}{\beta_{0}} e^{-.5\left[\frac{\ln \left(r / \alpha_{0}\right)}{\beta_{0}}\right]^{2}}+\frac{N_{1}}{\sqrt{2 \pi}} \frac{1}{\beta_{1}} e^{-.5\left[\frac{\ln \left(r / \alpha_{1}\right)}{\beta_{1}}\right]^{2}}
$$

Equation 4.

where $r$ is the particle radius in $\mu \mathrm{m}, N_{0}$ is the number density of particles in the Aitken mode in $\mathrm{cm}^{-3}$ and $\alpha_{0}$ and $\beta_{0}$ are the median radius in $\mu \mathrm{m}$ and the width of the Aitken mode, respectively; while $N_{1}, \alpha_{1}$, and $\beta_{1}$ are the corresponding parameters for the accumulation mode (note that $\beta=\ln (\mathrm{s})$ where $\mathrm{s}$ is the geometric standard deviation). ${ }^{11}$

The PBPSO algorithm generates 200 possible solutions and then calculates AODs using standard Mie theory for each of the 13 wavelengths for measured AODs. Particle Swarm Optimization algorithms are iterative algorithms that move a set of randomly generated solutions towards the solution that gives the best agreement with measured data. The $\overline{\chi^{2}}$ for the observed and calculated AODs is used to identify local minima for a single solution and a global minimum for the set of 200 solutions. All solutions are moved towards these minima with each iteration until the distribution parameters of the global minimum have changed by less than $.001 \%$ for 100 consecutive iterations. This process is repeated ten times so that a mean and standard deviation of the mean can be calculated for $N_{0}, \alpha_{0}, \beta_{0}, N_{1}, \alpha_{1}$, and $\beta_{1}$.

The comprehensive satellite images and atmospheric measurements from the National Aeronautics and Space Administration (NASA), National Oceanic and Atmospheric Administration (NOAA) and National Weather Service (NWS) provide an approach to verify the findings of ground-based solar spectrometers. Satellite data containing visual spectrum images, aerosol optical depth gradients, upper air charts, backward trajectory maps, and forest fire characteristics prove invaluable in determining where aerosol loads travel, how air moves at different pressures and altitudes in the atmosphere and what events cause deviations in aerosol optical depths around the world. ${ }^{12-14}$

Conducting atmospheric aerosol research in Central Minnesota provides an interesting perspective as the aerosol load should be substantially less than in metropolitan areas experiencing heavy anthropogenic aerosol emissions. ${ }^{5,15-17}$ By cross-referencing data 
produced by Saint John's University's solar spectrometer with various satellite images, backward air mass trajectories, and upper air charts in a similar manner as Niemi et al. 2015, ${ }^{15}$ it became possible to examine changes in particle size distributions during events that alter the composition and amount of aerosols present.

One such event occurred in the summer of 2017 when British Columbia (BC) exhibited ideal conditions to spark massive forest fires. ${ }^{18}$ These fires burned over 1.2 million hectares (over 4,600 square miles) and emitted an estimated 200 million tons of carbon dioxide equivalent into the atmosphere. ${ }^{18,19}$ The effects of these aerosols being introduced into the atmosphere have a short lifetime, but the immediate atmospheric effects can be seen by investigating the AOD and particle size distributions before, during, and at the end of the BC forest fires of 2017.

\section{METHODS AND PROCEDURES}

This research investigates the data from a ground-based solar spectrometer compared to NASA's Earth Observatory AOD data, NOAA Upper Air Charts, and satellite imagery from the GOES-13 satellite. ${ }^{20}$ The following steps outline how the data collected at Saint John's University was used in conjunction with satellite imagery and other resources to determine how particle size distributions changed throughout an episode related to the BC fires. The analysis procedure followed these steps:

Step 1: Analysis of the spread of the major BC forest fires of 2017 revealed that the original fires commenced after severe weather systems passed through on July 6-8, 2017 (day-of-year 187-189) and spread rapidly, culminating in the most massive fires connecting in Mid-August and the State of Emergency ending on September 15 (day 258).18

Step 2: Before analysis of the raw data from the solar spectrometer could begin, local atmospheric pressure data were obtained from the NOAA Radiosonde database, and global atmospheric $\mathrm{CO}_{2}$ data was collected from the Mauna Loa Observatory database with daily values interpolated from the given weekly averages. ${ }^{21,22}$ The $\mathrm{CO}_{2}$ and local pressure levels influence the calculated AOD and therefore affect the particle size distributions and the other products of this research.

Step 3: The data collected by the Kipp-Zonen PGS-100 Solar Spectrometer was converted from raw count data from the spectrometer into irradiance values by applying the manufacturer's calibration constants. The data were screened to eliminate measurements with significant cloud cover, judged by raw counts below 20,000 at $778 \mathrm{~nm}$. This wavelength was chosen as it is just past the large $\mathrm{O}_{2}$ absorption region and is not subject to strong Rayleigh scattering.

Step 4: The aforementioned atmospheric $\mathrm{CO}_{2}$ measurements from Step 2 were included in Equation 3 in order to calculate AOD across all wavelengths taking into account the new Rayleigh scattering term with adjustments for increasing $\mathrm{CO}_{2}$ levels. Details of this calculation are provided in Bodhaine et al. 1999.10

Step 4: Each day's AOD at thirteen key wavelengths was extracted: the standard World Meteorological Organization's (WMO) wavelengths: 412, 500, 610, 675, and $778 \mathrm{~nm}$; WMO wavelengths shifted out of absorption regions: 463,870 and $1020 \mathrm{~nm}$; and five additional wavelengths: 441, 479, 520, 556, $750 \mathrm{~nm} .{ }^{23}$ These specific wavelengths enable the visualization of aerosol optical depth without absorption from common gaseous atmospheric components.

Step 5: In order to better understand the AOD trends over Central Minnesota, Figure 1 was constructed using all of the AOD data from 2017. This gave valuable insights as to which date ranges would provide viable information.

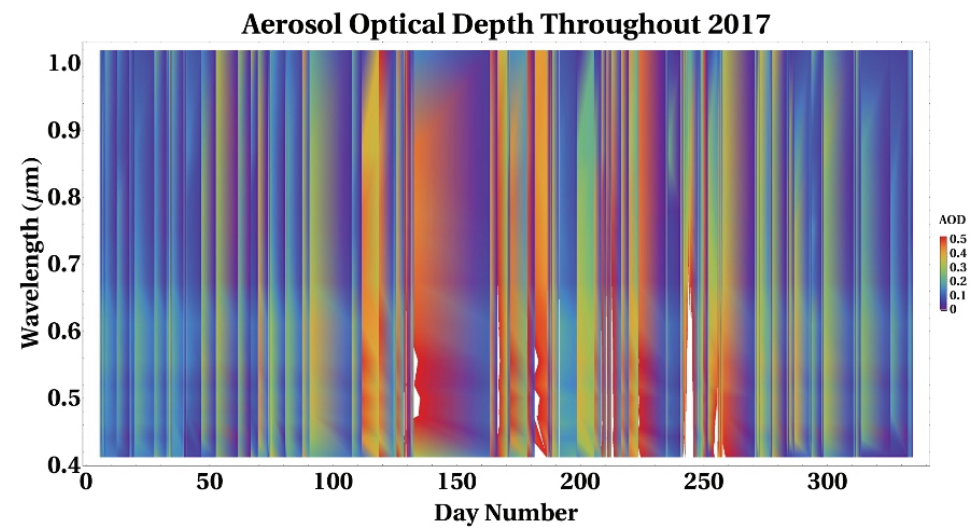

Figure 1. Surface visualization of the entire year (2017) of AOD data. This enabled the selection of viable date ranges around the time of the BC forest fires. The gaps in the data seen clearly between days 130-160 are due to significant cloud cover. 
Step 6: Comparing the AOD data in Figure 1 to the timeline of the BC forest fire revealed three preliminary dates of interest that correspond to times before, during, and after the wildfires. These dates: 15 June (166), 29 July (210) and 14 September (257) contain sufficient AOD data (significant cloud cover was not an issue).

Step 7: Figure 2 shows higher time-resolution spectra on the three specific dates of interest leading to a hypothesis that interesting particle size distribution data would be present during the times of the daily minimum and maximum AOD on each of these days.

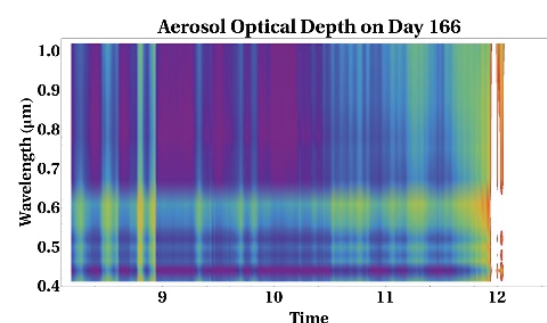

Figure 2.1

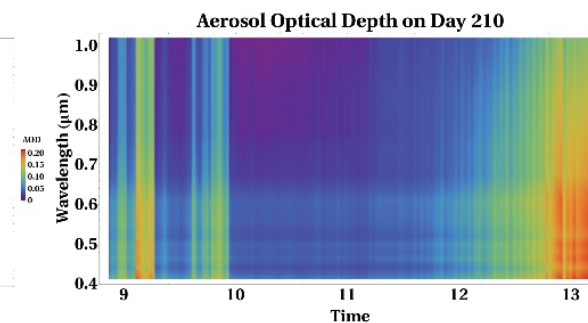

Figure 2.2

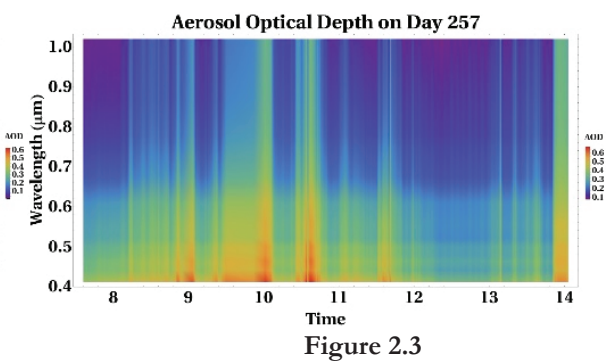

Figure 2.3

Figure 2. Surface plots of calculated AOD values. Figure 2.1 illustrates day 166 (15 June 2017), Figure 2.2 illustrates day 210 (29 July 2017 ), and Figure 2.3 illustrates day 257 (14 September 2017) in greater detail. The solar spectrometer re-aligning itself with the center of the sun's maximum intensity causes the vertical lines seen in these plots and the white sections, as seen on the far right of Figure 2.1 illustrate what occurs when the spectrometer excludes data due to cloud cover.

Step 8: The six selected times (maxima and minima AOD data on the three days) were then extracted from Figure 2 and illustrated in Figure 3 to show the variations in AOD across the spectrum of wavelengths at each time.

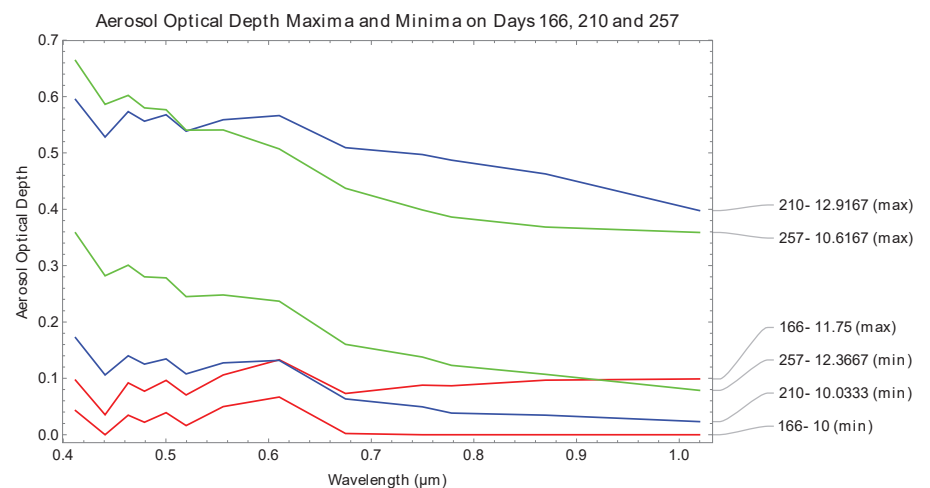

Figure 3. Graph of maxima (squares) and minima (circles) AOD on days 166, 210 and 257 depicts a clear increase in AOD at all wavelengths from June to July and September.

Step 9: To better understand the variations in AOD data throughout each day, the plots in Figure 2 were cross-referenced with satellite imagery in Figure 4 from NASA's GOES 13 geostationary satellite to determine if cloud cover or other sources of atmospheric aerosols likely caused the fluctuation in AOD data.

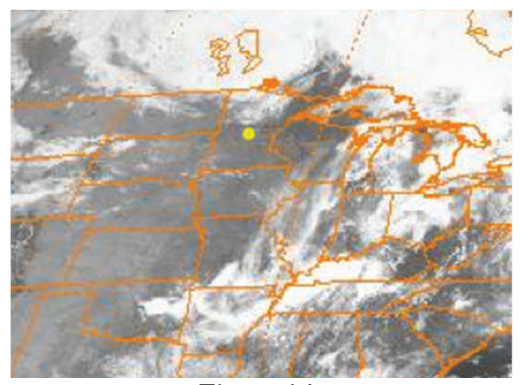

Figure 4.1

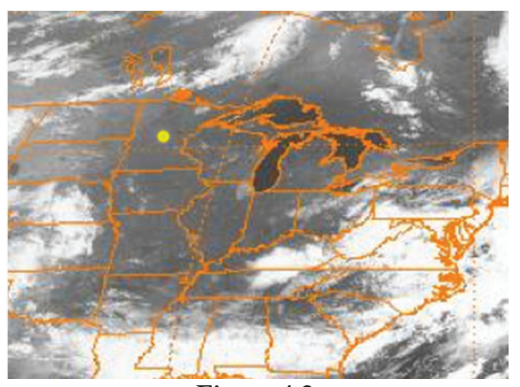

Figure 4.2

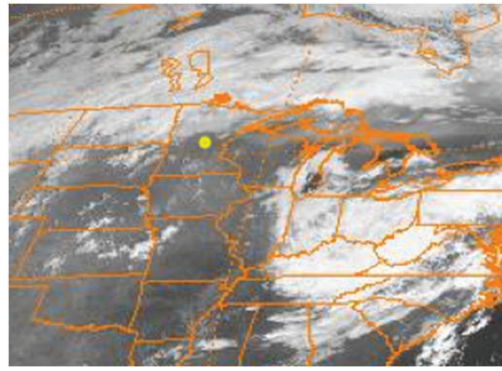

Figure 4.3

Figure 4. Satellite images from GOES 13 satellite showing cloud cover on 15 June 2017 in Figure 4.1, 29 July 2017 in Figure 4.2 and 14 September 2017 in Figure 4.3 each captured at 1445 UTC (9:45 a.m. local time in Minnesota). ${ }^{13}$ The yellow dot indicates the location of the solar spectrometer where data was collected. 
Step 10: Once the times of interest (maximum and minimum AOD) on days 166, 210, and 257 had been selected, the PBPSO algorithm was used to find the fit parameters of the bimodal lognormal particle size distribution shown in Equation $4 .^{11}$ The variables in Equation 4 correspond to different aspects of the bimodal distribution where $r$ is the particle radius in $\mu \mathrm{m}, N_{0}$ is the number density of particles in the Aitken mode in $\mathrm{cm}^{-3}$, and $\alpha_{0}$ and $\beta_{0}$ are the median radius in $\mu \mathrm{m}$ and the width of the Aitken mode, respectively; while $N_{1}, \alpha_{1}$, and $\beta_{1}$ are the corresponding parameters for the accumulation mode.

\section{RESULTS AND DISCUSSION}

Based on the evidence shown in Figure 4 that heavy cloud was not present over the site on the three days of interest, Upper Air Charts provided by National Oceanic and Atmospheric Administration (NOAA) and the National Weather Service (NWS) are used to illustrate the direction of air traveling from the BC region to the upper Midwest and Central Minnesota more specifically. ${ }^{24}$ Figure 5 shows the backward trajectories from NOAA Hybrid Single-Particle Lagrangian Integrated Trajectory (HYSPLIT) models, ${ }^{13}$ illustrating the plausibility that the particles in the atmosphere above Central Minnesota traveled from the Pacific Northwest or Southern BC, corresponding to the region of the major forest fires in this time period. An exception was found on day 257 when the HYSPLIT backward trajectories showed air masses moving towards Central Minnesota from the Pacific Northwest, but the NOAA upper air charts showed trajectories coming from Central California. This could elicit the irregular trend in AOD data on day 257, but does not change the results of the size distributions.

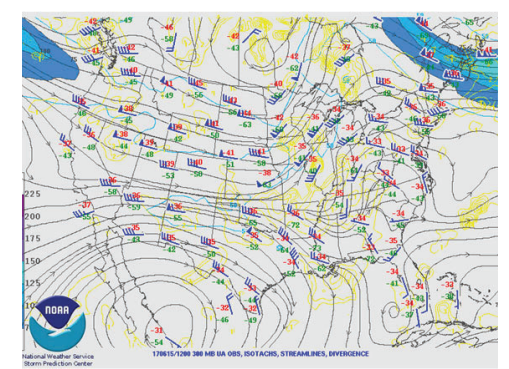

Figure 5.1. Day 166 NOAA HYSPLIT MODEL Backward trajectories ending at 1900 UTC 15 Jun 17

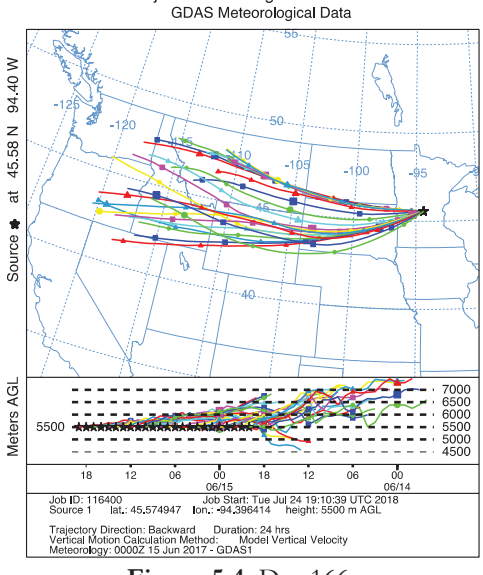

Figure 5.4. Day 166

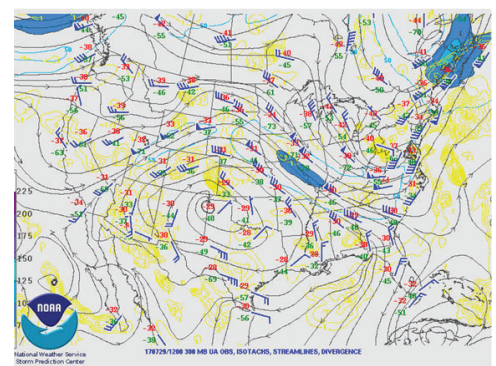

Figure 5.2. Day 210

NOAA HYSPLIT MODEL

Backward trajectories ending at 1900 UTC 29 Jul 17

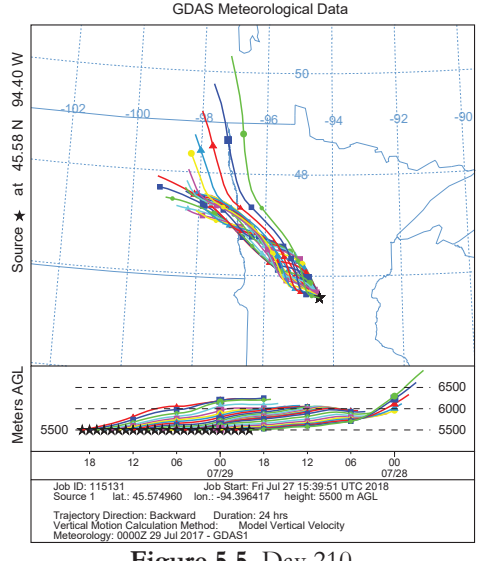

Figure 5.5. Day 210

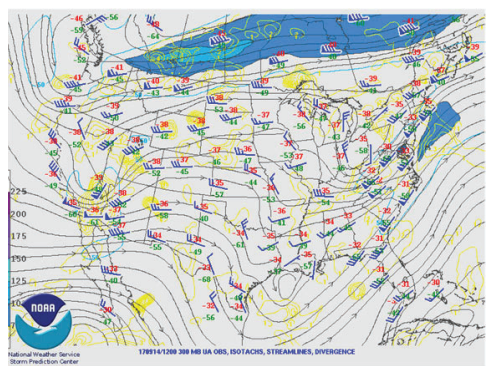

Figure 5.3. Day 257 Backward trajectories ending at 1900 UTC 14 Sep 17 GDAS Meteorological Data

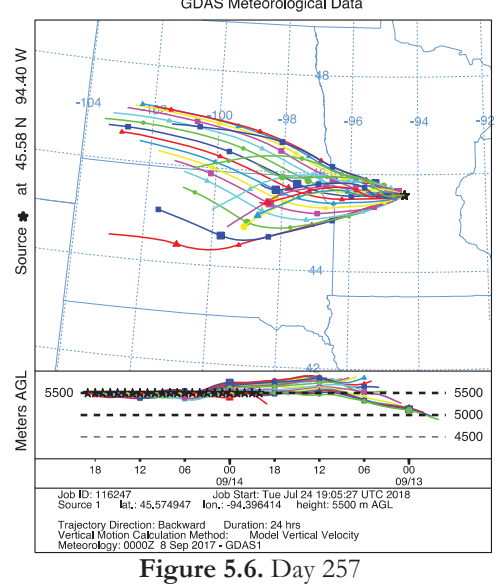

Figure 5. Figures 5.1-5.3 NOAA Storm Prediction Center Upper Air charts depicting the air patterns at $300 \mathrm{mb}$ or roughly $5500 \mathrm{~m}$ above ground level. Figure 5.4-5.6 NOAA HYSPLIT backward trajectories of air masses $5500 \mathrm{~m}$ above ground level (AGL) ending at the Saint John's University observatory where the solar spectrometer is located. ${ }^{10}$

With the understanding that on days 166, 210, and 257 the atmospheric aerosols above Central Minnesota likely came from near BC, the particle size distributions in Figures 6-8 carry information regarding how the combustion products suspended in the atmosphere from the forest fire affected particle size distributions. Chemically processed particles from combustion contribute to the Aitken mode portion of the bimodal distribution while mechanically generated particles contribute to the accumulation mode. As an air mass ages, it is expected that collisions will shift all particles toward larger radii.

On the specific days of interest, the PBPSO algorithm was run to generate bimodal distributions while allowing all fit parameters to vary. Based on information in Hodzic et al. 2007, forest fires primarily ( $80-90 \%$ by mass) emit aerosols with radii $<1.0 \mu \mathrm{m},{ }^{25}$ the bimodal distributions should illustrate how the aerosol loads changed with respect to the smaller particles with radii in the Aitken mode $(.02-.10 \mu \mathrm{m})$, but aerosols in the accumulation mode $(.10-1.0 \mu \mathrm{m})$ may form as the air mass ages during transport. ${ }^{3}$ Analysis 
of the bimodal distribution parameters accurately quantifies the broad spectrum variations in atmospheric aerosol loads as evidenced by their low $\overline{\chi^{2}}$ averages. These distributions, illustrated in Figures 6-8, highlight the transformation of both the Aitken and accumulation modes from day 166 to 210 to 257 at both the daily minimum and maximum AOD.

Diurnal Comparisons

On each of the selected days, different trends arise in the fit parameters between the minima and maxima AOD. The resulting parameters show that on each of the selected days, the number density of accumulation mode particles increases from the minimum to maximum AOD, while the median radius and width of distribution in the accumulation mode remain constant within uncertainty. Additionally, on the two days when BC forest fire aerosols are possibly present, the number density of Aitken mode particles is also constant within uncertainty. This suggests that throughout any given day, the number of larger particles and AOD are positively correlated, but when smoke and ash particles are likely present (Tables $\mathbf{2}$ and $\mathbf{3}$ ), the number of smaller radii particles remains stable with increasing AOD.

\section{Daily Minima Comparisons}

To better understand the results of the distributions in regards to potential smoke in the atmosphere, each distribution fit parameter was evaluated. When looking at the Aitken mode parameters of the daily minima AODs, the $\mathrm{N}_{0}$ increases by roughly an order of magnitude from day 166 to 210 and again from 210 to 257, $\alpha_{0}$ decreases by about 20\% from each day to the next, $\beta_{0}$ is constant within uncertainty on days 166 and 210 but nearly doubles on day 257. Looking at the accumulation mode parameters, $\mathrm{N}_{1}$ remains constant within uncertainty on days 166 and 210 and increases by 100 on day 257, $\alpha_{1}$ increases from day 166 to 210 and remains constant within uncertainty on days 210 and 257, and $\beta_{1}$ remains constant within uncertainty between days 166 and 210 and also between days 210 and 257. Analyzing how these parameters evolve over time illustrates how each mode of particles changes.

The steady increase in $\mathrm{N}_{0}$ indicates many more particles with radii between $.01-.10 \mu \mathrm{m}$ present on days 210 and 257 compared to 166. Based on the steady decrease in $\alpha_{0}$, the median radius of these small particles decreases, which suggests an influx of small radii aerosols, consistent with combustion aerosols from forest fire emissions. The steady $\beta_{0}$ values depict a relatively constant spread in particle radii throughout the range of dates.

The PBPSO algorithm has difficulties illustrating the trends of larger particles in bimodal distributions due to the relatively flat Mie extinction profiles at larger radii. ${ }^{11}$ The accumulation mode results show that as time progressed, the median radius, $\alpha_{1}$, increased from day 166 to day 210 and then the number of particles, $N_{1}$, increased from day 210 to day 257 while the width of the distribution, $\beta_{1}$, remained constant within uncertainty across all of the days.

\section{Daily Maxima Comparisons}

The size distributions from the daily maxima AOD showed a similar trend as the daily minima in the fit parameters $\mathrm{N}_{0}$ and $\alpha_{0}$ illustrating an increase in particles in the Aitken mode with smaller median radii, but the $\beta_{0}$ values indicate a wider distribution of radii from day 166 to day 210 and then a narrower distribution from day 210 to day 257. This suggests that the increase in Aitken mode aerosols was due to an influx of smaller radius particles. Another interesting result arises in the accumulation mode of the daily maxima AOD size distributions where $\mathrm{N}_{1}$ and $\alpha_{1}$ values remain constant within uncertainty across all three days, and $\beta_{1}$ is seen to increase from day 166 to day 210 and then remain constant within uncertainty. This result suggests that while the number and median radius of particles remains constant, the variation in particle radius in the accumulation mode may increase when smoke from forest fires is present due to the rapidly changing size distributions caused by differences in transport height. 
Day 166 Minimum AOD at 10:00

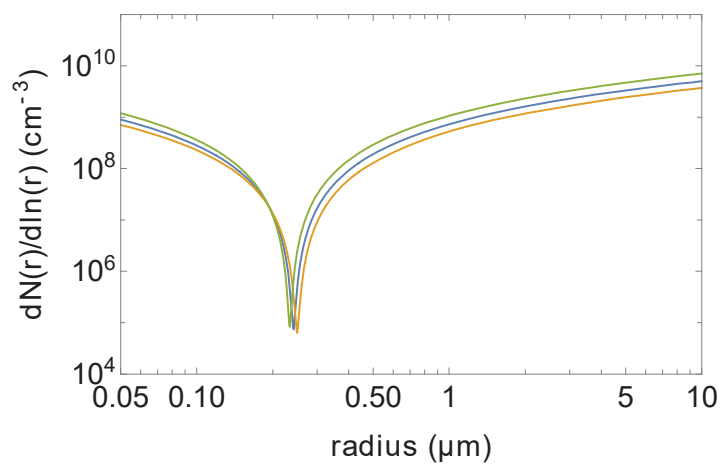

Figure 6.1
Day 166 Maximum AOD at 11:45

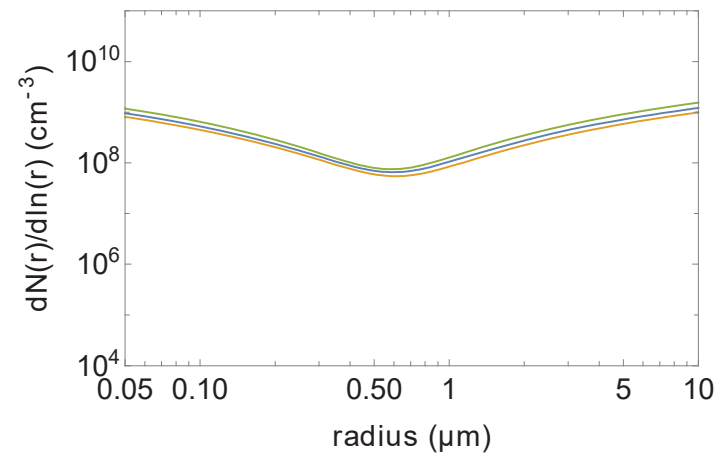

Figure 6.2

Figure 6. Bimodal Distributions from day 166 at 1000 in Figure 6.1 and at 1145 in Figure 6.2. Shading indicates uncertainty in distribution parameters.

\begin{tabular}{|c|c|c|c|c|c|c|c|}
\hline & $\begin{array}{c}\overline{\chi^{2}} \\
\text { average }\end{array}$ & $\begin{array}{c}\mathrm{N}_{0} \pm \mathrm{SDOM} \\
\left(\mathrm{cm}^{-3}\right)\end{array}$ & $\begin{array}{c}\alpha_{0} \pm \\
\text { SDOM } \\
(\mu \mathrm{m})\end{array}$ & $\begin{array}{c}\beta_{0} \pm \\
\mathrm{SDOM}\end{array}$ & $\begin{array}{c}\mathrm{N}_{1} \pm \\
\mathrm{SDOM} \\
\left(\mathrm{cm}^{-3}\right)\end{array}$ & $\begin{array}{c}\alpha_{1} \pm \text { SDOM } \\
(\mu \mathrm{m})\end{array}$ & $\begin{array}{c}\beta_{1} \pm \\
\text { SDOM }\end{array}$ \\
\hline $\begin{array}{c}166-1000 \\
\text { (Figure 6.1) }\end{array}$ & .03 & $\begin{array}{c}5.5 \times 10^{6} \pm \\
5 \times 10^{5}\end{array}$ & $\begin{array}{l}.242 \pm \\
8 \times 10^{-3}\end{array}$ & $.15 \pm .02$ & $\begin{array}{c}1.006 \times 10^{3} \pm \\
5\end{array}$ & $1.5 \pm .3$ & $.22 \pm .02$ \\
\hline $\begin{array}{c}166-1145 \\
\text { (Figure 6.2) }\end{array}$ & .008 & $\begin{array}{c}1.0 \times 10^{6} \pm \\
2 \times 10^{5}\end{array}$ & $.40 \pm .03$ & $.13 \pm .01$ & $\begin{array}{c}6 \times 10^{5} \pm \\
1 \times 10^{5}\end{array}$ & $1.9 \pm .5$ & $.16 \pm .04$ \\
\hline
\end{tabular}

Table 1. Data table containing mean fit parameter and standard deviations from day 166's Bimodal Distributions in Figure 6. The Aitken mode parameters $\mathrm{N}_{0}$, $\alpha_{0}$, and $\beta_{0}$ between 10:00 and 11:45 show the number density decreasing, the radius increasing and the width of distribution remaining constant suggesting that coalescence of the smaller particles occurs.

Day 210 Minimum AOD at 10:02

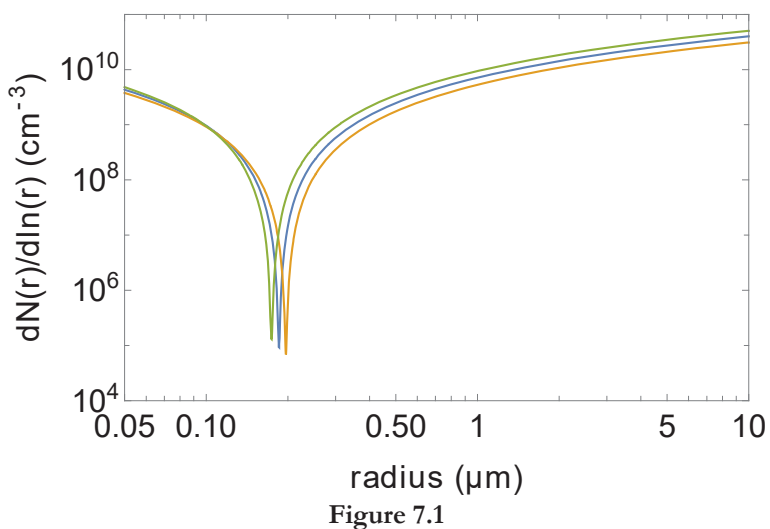

Day 210 Maximum AOD at 12:55

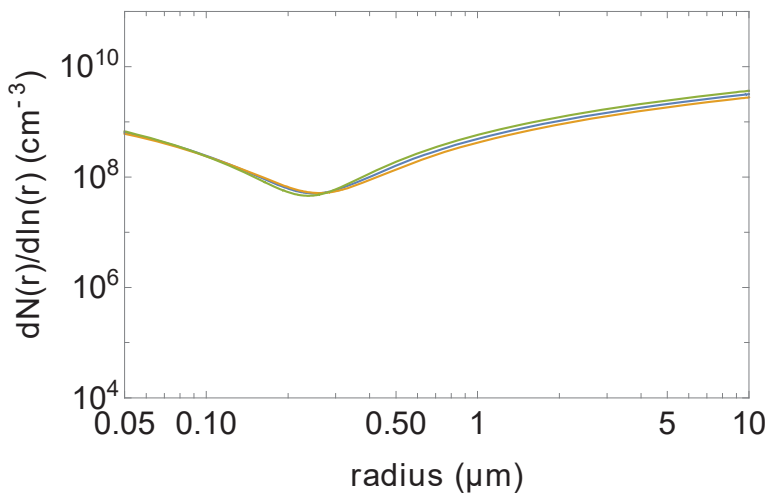

Figure 7.2

Figure 7. Bimodal Distributions from day 210 at 1002 (minimum AOD) in Figure 7.1 and at 1255 (maximum AOD) in Figure 7.2. Shading indicates uncertainty in distribution parameters.

\begin{tabular}{|c|c|c|c|c|c|c|c|}
\hline & $\begin{array}{c}\overline{\chi^{2}} \\
\text { average }\end{array}$ & $\begin{array}{c}\mathrm{N}_{0} \pm \mathrm{SDOM} \\
\left(\mathrm{cm}^{-3}\right)\end{array}$ & $\begin{array}{c}\alpha_{0} \pm \text { SDOM } \\
(\mu \mathrm{m})\end{array}$ & $\begin{array}{c}\beta_{0} \pm \\
\mathrm{SDOM}\end{array}$ & $\begin{array}{c}\mathrm{N}_{1} \pm \mathrm{SDOM} \\
\left(\mathrm{cm}^{-3}\right)\end{array}$ & $\begin{array}{c}\alpha_{1} \pm \text { SDOM } \\
(\mu \mathrm{m})\end{array}$ & $\begin{array}{c}\beta_{1} \pm \\
\text { SDOM }\end{array}$ \\
\hline $\begin{array}{c}210-1002 \\
\text { (Figure 7.1) }\end{array}$ & .007 & $\begin{array}{c}6 \times 10^{7} \pm \\
2 \times 10^{7}\end{array}$ & $.19 \pm .01$ & $.18 \pm .03$ & $1.03 \times 10^{3} \pm 30$ & $2.6 \pm .5$ & $.26 \pm .04$ \\
\hline $\begin{array}{c}210-1255 \\
\text { (Figure } 7.2 \text { ) }\end{array}$ & .001 & $\begin{array}{c}5.0 \times 10^{7} \pm \\
5 \times 10^{6}\end{array}$ & $.227 \pm .008$ & $.38 \pm .03$ & $\begin{array}{c}8 \times 10^{5} \pm \\
3 \times 10^{5}\end{array}$ & $2.5 \pm .4$ & $.28 \pm .03$ \\
\hline
\end{tabular}

Table 2. Data table containing mean fit parameter and standard deviations from day 210's Bimodal Distributions in Figure 7. 
Day 257 Minimum AOD at 12:22

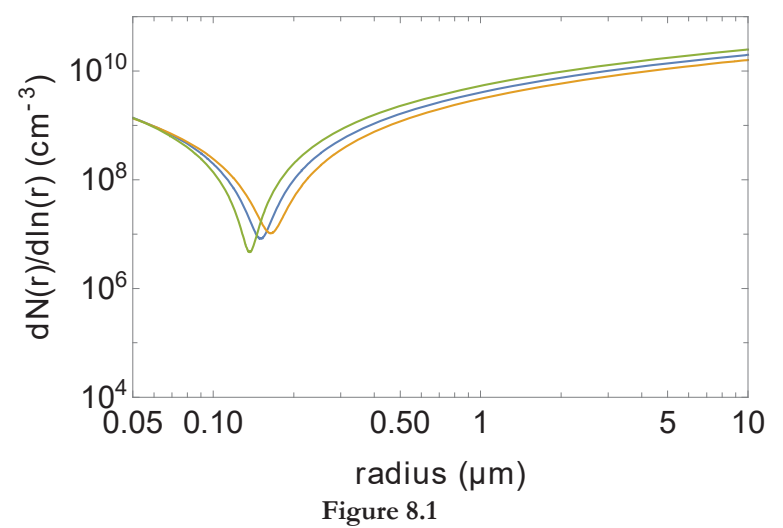

Day 257 Maximum AOD at 10:37

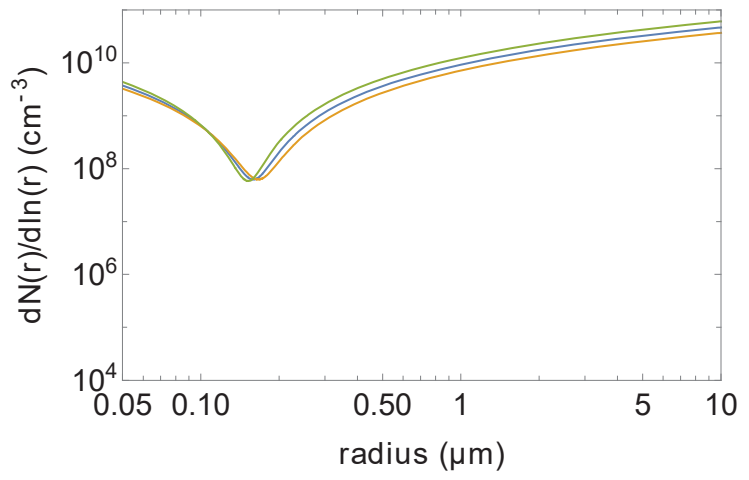

Figure 8.2

Figure 8. Bimodal Distributions from day 257 at 1222 (minimum AOD) in Figure 8.1 and at 1037 (maximum AOD) in Figure 8.2. Shading indicates uncertainty in distribution parameters.

\begin{tabular}{|c|c|c|c|c|c|c|c|}
\hline & $\begin{array}{c}\overline{\chi^{2}} \\
\text { average }\end{array}$ & $\begin{array}{c}\mathrm{N}_{0} \pm \mathrm{SDOM} \\
\left(\mathrm{cm}^{-3}\right)\end{array}$ & $\begin{array}{c}\alpha_{0} \pm \text { SDOM } \\
(\mu \mathrm{m})\end{array}$ & $\begin{array}{c}\beta_{0} \pm \\
\operatorname{SDOM}\end{array}$ & $\begin{array}{c}\mathrm{N}_{1} \pm \mathrm{SDOM} \\
\left(\mathrm{cm}^{-3}\right)\end{array}$ & $\begin{array}{c}\alpha_{1} \pm \text { SDOM } \\
(\mu \mathrm{m})\end{array}$ & $\begin{array}{c}\beta_{1} \pm \\
\text { SDOM }\end{array}$ \\
\hline $\begin{array}{c}257-1222 \\
\text { (Figure 8.1) }\end{array}$ & $\begin{array}{c}0 \\
.002\end{array}$ & $\begin{array}{c}1.6 \times 10^{8} \pm \\
3 \times 10^{7}\end{array}$ & $.15 \pm .01$ & $.33 \pm .04$ & $\begin{array}{c}1.2 \times 10^{5} \pm \\
6 \times 10^{4}\end{array}$ & $2.2 \pm .4$ & $.29 \pm .03$ \\
\hline $\begin{array}{c}257-1037 \\
\text { (Figure 8.2) }\end{array}$ & .0009 & $\begin{array}{c}1.6 \times 10^{8} \pm \\
2 \times 10^{7}\end{array}$ & $.158 \pm .007$ & $.24 \pm .03$ & $\begin{array}{c}9 \times 10^{5} \pm \\
2 \times 10^{5}\end{array}$ & $2.5 \pm .4$ & $.30 \pm .03$ \\
\hline
\end{tabular}

Table 3. Data table containing mean fit parameter and standard deviations from day 257's Bimodal Distributions in Figure 8.

\section{CONCLUSIONS}

The forest fire season of 2017 in BC emitted large amounts of atmospheric aerosols that dispersed over much of North America. ${ }^{19}$ The synthesis of satellite imagery, backward air mass trajectories, and upper air maps all aided in understanding the findings of aerosol optical depth calculations and particle size distributions generated from solar spectrometer data in Central Minnesota. Three specific days in the summer of 2017 that correspond to times before, during, and after the BC forest fires were selected based on the atmospheric conditions, meteorological patterns, and air mass trajectories present. Data collected on these days was used to calculate aerosol optical depths which could be input into a PBPSO algorithm in order to generate particle number size distributions that illustrate how the aerosol load above Central Minnesota changed during the fires.

The primary causes for uncertainty in the results come from the fact that aerosol emissions have very different lifetimes of suspension, range in dispersion, and composition based on a wide range of factors including emission type, environmental setting, and atmospheric conditions. The aerosols emitted by these forest fires are assumed to be primary particulate matter (PPM) with a relatively high injection altitude based on the findings of Hodzic et al. facilitating a potential for long-range transport while acknowledging that aging and secondary formation could occur during the transport. The characteristics of previously studied forest fire aerosols correlate to the likelihood of the particles from the 2017 BC fires bearing similar optical and physical properties as well as the likelihood of being suspended in the upper atmosphere while passing over Central Minnesota. ${ }^{25}$

These aerosol size distributions show the variations in the number of particles in each mode. $\mathrm{N}_{1}$ values are seen to steadily increase from each day's minimum to maximum $\mathrm{AOD}$, whereas $\mathrm{N}_{0}$ remains constant when smoke is likely present. In contrast, analyzing the data across the three days, $\mathrm{N}_{0}$ steadily increases while $\mathrm{N}_{1}$ remains constant excluding the minimum AOD on day 257 when there was likely some cloud cover compared to the other days experiencing relatively clear skies. Additionally, Aitken mode parameter values from day 166 to 210 to 257 show a decreasing median radius combined with an increasing number of particles in accordance with the understanding that forest fires emit a majority of aerosols with radii $<1 \mu \mathrm{m} .{ }^{25}$ During the periods of clean air, variations in AOD appear to be induced by both particle sizes and number concentrations. In contrast, during periods of smoke presence, only moderate shifts in size distribution were observed while number concentrations of small particles increased by an order of magnitude or more.

Comparing the size distributions across each of the daily minima AOD, the parameters show that across all three days in the Aitken mode, the number of particles increases while the median radius decreases. Additionally, from day 210 to 257, the width of the Aitken mode distribution increases, and the number of particles in the accumulation mode increase. These patterns suggest 
that even with varying cloud cover as indicated by accumulation mode parameters the solar spectrometer can collect accurate data about the number of Aitken mode particles as well as their median radius and width of distribution.

The generated size distributions across each of the daily maxima AOD showed different trends in particle radii, number densities, and width of distributions, but some of these anomalies are likely due to the sensor collecting data during moderate cloud cover. The major outcomes of the fit parameters from day 166 to 210 to 257 show that in the Aitken mode, the number of particles increases and the median radius decreases while in the accumulation mode, the number of particles and the median radius remains constant within uncertainties across all three days while the width of distribution increased from day 166 to 210.

In terms of future work in this field, data from terrestrial solar spectrometers can be analyzed through the PBPSO algorithm in order to generate bimodal lognormal size distributions that give valuable insights into the Aitken mode number distribution, median radius, and width of distribution even when the algorithm experiences difficulty precisely determining accumulation mode parameters under heavy aerosol loads or cloud cover.

\section{ACKNOWLEDGMENTS}

The authors thank the College of Saint Benedict and Saint John's University for the opportunity to conduct research in outstanding facilities and for their generous grant that made this work possible.

\section{REFERENCES}

1. Prijith, S., Rao, P., Mohan, M., Sai, M. and Ramana, M. (2018) Trends of absorption, scattering and total aerosol optical depths over India and surrounding oceanic regions from satellite observations: role of local production, transport and atmospheric dynamics, Environ Sci Pollut Res. https:/ / doi.org/10.1007/s11356-018-2032-0

2. Baron, P. (2010) Generation and behavior of airborne particles (aerosols), Centers for Disease Control and Prevention, https:// wmw.cdc.gov/niosh/topics/aerosols/pdfs/_Aerosol_101.pdf(accessed Jul 2018)

3. Yue, D., Hu, M., Wu, Z., Wang, Z., Guo, S., Wehner, B., Nowak, A., Achert, P., Wiedensohler, A., Jung, J., Kim, Y. and Liu, S. (2009) Characteristics of aerosol size distributions and new particle formation in the summer in Beijing, J. Geophys. Res., 114. bttps:// doi.org/10.1029/2008JD010894

4. Ramachandran, S., Srivastava, R., Kedia, S., and Rajesh, T.A. (2012) Contribution of natural and anthropogenic aerosols to optical properties and radiative effects over an urban location. Environ Res Lett 7, 034028. https://doi.org/10.1088/17489326/7/3/034028

5. Poschl, U. (2005) Atmospheric aerosols: composition, transformation, climate and health effects, Agnew Chem Int Ed Engl 44, 7520-7540. https:// doi.org/10.1002/ anie.200501122

6. Mao, J. and Li, J. (2015) Retrieval of particle size distributions from aerosol optical thickness using an improved particle swarm optimization algorithm, Opt Rev 22, 809-818. https://doi.org/10.1007/s10043-015-0130-5

7. Li, S., M. J. Garay, L. Chen, E. Rees, and Y. Liu (2013), Comparison of GEOS-Chem aerosol optical depth with AERONET and MISR data over the contiguous United States, J Geophys Res Atmos 118, 11,228-11,241. https://doi.org/10.1002/jgrd.50867

8. London, J. (1985) The Observed Distribution of Atmospheric Ozone and Its Variations, in Orone in the Free Atmosphere (Whitten, R. C. and Prasad, S. S., Eds.), 11-80, Van Nostrand Reinhold, NY.

9. U.S. Department of Energy (DOE)/National Renewable Energy Laboratory (NREL)/Alliance for Sustainable Energy, LLC (ALLIANCE). "Solar Spectra: Standard Air Mass Zero," E490_00a_AM0.xls spreadsheet, http:/ / rredc.nrel.gov/solar/spectra/am0/ASTM2000.html (accessed Jul 2018)

10. Bodhaine, B. A., Wood, N. B., Dutton, E. G., and Slusser, J. R. (1999) On Rayleigh optical depth calculations, J Atmos Ocean Tech 16, 1854-1861. https:// doi.org/10.1175/1520-0426(1999)016<1854:ORODC>2.0.CO;2

11. DuPaul, K.M. and Whitten, A.T. (2017) Determination of Fitted Size Distribution for Atmospheric Aerosols, Am J Undergrad Res 14(2), 105-115. bttps:// doi.org/10.33697/ ajur.2017.018

12. Knapp, K. R. (2008) Scientific data stewardship of International Satellite Cloud Climatology Project B1 global geostationary observations, J Applied Remote Sensing 2, 023548. https:/ / doi.org/10.1117/1.3043461

13. Stein, A.F., Draxler, R.R, Rolph, G.D., Stunder, B.J.B., Cohen, M.D., and Ngan, F. (2015) NOAA's HYSPLIT atmospheric transport and dispersion modeling system, Bull Amer Meteor Soc 96, 2059-2077. https://doi.org/10.1175/BAMS-D-14-00110.1

14. Knapp, K. R., Frouin, R., Kondragunta, S. and Prados, A. (2005) Toward aerosol optical depth retrievals over land from GOES visible radiances: determining surface reflectance, Int J Remote Sensing, 26:18, 4097-4116. bttps:/ / doi.org/10.1080/01431160500099329

15. Niemi, J. V., Tervahattu, H., Vehkamaki, H., Martikainen, J., Laakso, L., Kulmala, M., Aarnio, P., Koskentalo, T., Sillan, M., Makkonen, U. (2005) Characterization of aerosol particle episodes in Finland caused by wildfires in Eastern Europe, Atmos Chem Phys 5, 2299-2310. bttps:/ / doi.org/10.5194/acp-5-2299-2005

16. Chin, M., Diehl, T., Ginoux, P., Malm, W. (2007) Intercontinental transport of pollution and dust aerosols: implications for regional air quality, Atmos Chem Phys 7, 5501-5517. https:// doi.org/10.5194/ acp-7-5501-2007 
17. Marley, N. and Gaffney, J. (2005) Introduction to Urban Aerosols and Their Impacts, ACS Symposium Series, American Chemical Society, Washington, DC, https://pubs.acs.org/doi/pdf/10.1021/bk-2006-0919.ch001 (accessed Jul 2018)

18. British Columbia Wildfire Service (2017) Wildfire Season Summary, BC Wildfire Service, bttps:// www2.gov.bc.ca/gov/content/safety/wildfire-status/about-bcws/wildfire-bistory/ wildfire-season-summary (accessed Jul 2018)

19. Ciolfe, T. (2017) B.C. wildfires set record high greenhouse gas emission levels, Maclean's, bttps:/ / www.macleans.ca/ news/ canada/ b-c-wildfires-set-record-high-greenhouse-gas-emission-levels/ (accessed Aug 2018)

20. Levy, R. and Hsu, C. (2015) MODIS Atmosphere L2 Aerosol Product, NASA MODIS Adaptive Processing System, Goddard Space Flight Center, USA, http:/ / dx.doi.org/10.5067/MODIS/MOD04_L2.006 (Terra) and bttp:/ / dx.doi.org/10.5067/MODIS/MYD04_L2.006 (Aqua) (accessed Aug 2018)

21. Tans, P., (2018) Trends in Atmospheric Carbon Dioxide, NOAA/ESRL, www.esrl.noaa.gov/gmd/ccgg/trends/ (accessed Jul 2018)

22. Govett, M. (2018) NOAA/ESRL Radiosonde Database, https:// ruc.noaa.gov/ raobs/ (accessed Jul 2018)

23. GAW Report No. 227 (2016), WMO/GAW Aerosol Measurement Procedures, Guideline, and Recommendations, 2nd Edition, World Meteorological Organization, Switzerland.

24. NOAA/National Weather Service (2018) Storm Prediction Center Surface and Upper Air Maps, NOAA's National Weather Service Storm Prediction Center, https:// wmw.spc.noaa.gov/ obswx/maps/ (accessed Jul 2018)

25. Hodzic, A., Madronich, S., Bohn, B., Massie, S., Menut, L. and Wiedinmyer, C. (2007) Wildfire particulate matter in Europe during summer 2003:mesoscalee modeling of smoke emissions, transpor, and radiative effects, Atmos Chem Phys 7, $4043-4064$. bttps:/ / doi.org/10.5194/acp-7-4043-2007

\begin{abstract}
ABOUT STUDENT AUTHOR
Dane Kuhr is from Lakeville, Minnesota and will graduate in May 2020 with a B.A. in Applied Physics and an emphasis on PreEngineering. After spending the summer before his Junior year researching atmospheric aerosols, Dane will be developing models of atmospheric attenuation in concentrating solar power (CSP) systems at the National Renewable Energy Laboratory in Golden, $\mathrm{CO}$ before applying to graduate programs in Mechanical Engineering next year. His passion for serving others motivates him to work towards sustainable solutions in the renewable energy sector.
\end{abstract}

\title{
PRESS SUMMARY
}

Aerosol optical depths (AODs) were calculated from solar irradiance values collected by a Kipp-Zonen PGS-100 solar spectrometer. These AODs collected throughout 2017 were then compared to satellite imagery, upper air chart, and wind patterns to determine when air masses moved from the British Columbia region towards Central Minnesota during the BC forest fires. The AOD data from three selected days (20170615, 20170729 and 20170914) was input into a parameter based particle swarm optimization (PBPSO) algorithm to generate particle number size distributions. The generated bimodal lognormal size distributions at each of the three selected day's maxima and minima AOD illustrate an increase in the number of smaller particles with radii in the Aitken mode during the forest fires compared to the distributions before the emission of forest fire particles. The results of these number size distributions verify that the data from ground-based solar spectrometers can be used in the PBPSO algorithm to detect variations in the number, radius, and width of the distribution of particles in the Aitken mode during events like forest fires. 